\title{
Diagnosis of avulsion fractures of the distal fibula after lateral ankle sprain in children: a diagnostic accuracy study comparing ultrasonography with radiography
}

Yoshiyuki Takakura', Satoshi Yamaguchi ${ }^{2,3^{*}}$, Ryuichiro Akagi $i^{3}$, Makoto Kamegaya ${ }^{4}$, Seiji Kimura ${ }^{3}$, Hirofumi Tanaka ${ }^{5}$ and Tetsuro Yasui ${ }^{6}$

\begin{abstract}
Background: The purpose of this study was to determine the diagnostic accuracy of ultrasonography for the diagnosis of avulsion fractures of the distal fibula for lateral ankle sprain in children and compare it to that of radiography.
\end{abstract}

Methods: Children who sustained lateral ankle sprain were prospectively surveyed. They underwent both ultrasonography and radiography at the first clinic visit to diagnose any concomitant avulsion fractures of the distal fibula. The patients underwent follow-up radiography 4 weeks later to obtain the reference standard diagnosis. The measures of diagnostic accuracy (i.e., sensitivity, specificity, positive predictive value, and negative predictive value) of the initial ultrasonography and radiography were calculated; they were then compared using the McNemar test. Totally, 52 patients (with a median age of 9 years) were analyzed.

Results: On the reference standard (follow-up) radiographs, 32 patients (62\%) were found to have avulsion fractures of the distal fibula. The sensitivity, specificity, positive predictive value, and negative predictive value for ultrasonography were $94,85,91$, and $89 \%$ respectively; and $81,100,100$, and $77 \%$ respectively for radiography at the first visit. There were no significant differences in sensitivity and specificity between the two diagnostic methods $(P=0.22,0.25)$.

Conclusions: Ultrasonography has a high diagnostic accuracy, which is comparable to that of radiography, for the diagnosis of avulsion fracture of the distal fibula. Ultrasonography may be used as an option of imaging modality for lateral ankle sprain in children.

Keywords: Lateral ankle sprain, Avulsion fracture, Diagnostic accuracy, Pediatrics, Radiography, Subfibular ossicle, Ultrasonography

\footnotetext{
*Correspondence: y-satoshi@mvb.biglobe.ne.jp

${ }^{2}$ Collage of Liberal Arts and Sciences, Chiba University, 1-8-1 Inohana,

Chuo-ku, Chiba-shi, Chiba 260-8670, Japan

${ }^{3}$ Department of Orthopaedic Surgery, Graduate School of Medical and

Pharmaceutical Sciences, Chiba University, 1-8-1 Inohana, Chuo-ku, Chiba-shi,

Chiba 260-8670, Japan

Full list of author information is available at the end of the article
}

\section{$\triangle B M C$}

(c) The Author(s). 2020 Open Access This article is licensed under a Creative Commons Attribution 4.0 International License, which permits use, sharing, adaptation, distribution and reproduction in any medium or format, as long as you give appropriate credit to the original author(s) and the source, provide a link to the Creative Commons licence, and indicate if changes were made. The images or other third party material in this article are included in the article's Creative Commons licence, unless indicated otherwise in a credit line to the material. If material is not included in the article's Creative Commons licence and your intended use is not permitted by statutory regulation or exceeds the permitted use, you will need to obtain permission directly from the copyright holder. To view a copy of this licence, visit http://creativecommons.org/licenses/by/4.0/ The Creative Commons Public Domain Dedication waiver (http://creativecommons.org/publicdomain/zero/1.0/) applies to the data made available in this article, unless otherwise stated in a credit line to the data. 


\section{Background}

Lateral ankle sprain is one of the most common injuries that occurs in daily living and sports activities. The incidence rate is higher in children (aged $\leq 12$ years, 2.85/ 1000 exposures) than in adolescents (aged $\geq 13$ to $\leq 17$ years, 1.94/1000 exposures) and adults (aged $\geq 18$ years, $0.72 / 1000$ exposures) [1]. Avulsion fractures of the distal fibula, which is the insertion of the anterior talofibular ligament (ATFL) and calcaneofibular ligament (CFL) [2], frequently occur concomitantly with lateral ankle sprain in children with an incidence as high as 60 to $70 \%$ [3-5]. Several studies have shown that a majority of children with lateral ankle sprain returned to daily activity within 1 to 3 months regardless of the presence of avulsion fracture [6]. However, patients with avulsion fractures have a higher risk of recurrent sprain occurring within 2 years than patients without avulsion fractures [5]. Moreover, most fractures fail to unite and persist as subfibular ossicles [5], which may cause chronic ankle pain and instability, and result in ankle osteoarthritis in the long term [7]. The presence of avulsion fractures could also affect the treatment plan. For ankle sprains without fractures, symptomatic or functional treatment using a brace is appropriate. However, for injuries with avulsion fractures, cast immobilization may be necessary to achieve bone union [8]. Therefore, the presence or absence of avulsion fracture is clinically important, as it can affect the prognosis and treatment of the injury.

Radiography is currently the gold standard for the diagnosis of fractures. However, diagnosis of avulsion fracture is difficult using standard radiographs of the ankle as more than half of the fractures are not visible on anteroposterior and lateral views $[5,9]$. Specialized radiographic projections, such as the ATFL and CFL views [10], can visualize avulsion fractures effectively, but at the cost of additional expense and radiation exposure. Although radiography uses low-dose radiation, exposure to this hazard may have a cumulative effect on pediatric patients because the growing bone is vulnerable to radiation injury [11]. Furthermore, small fracture fragments and chondral avulsions may not be detected even if these projections are used $[8,12]$. The Ottawa Ankle Rules are commonly used clinical examination rules to identify patients with ankle injuries that do not require radiographic examination [13]. Although the rules have high diagnostic accuracy in excluding ankle fractures, their sensitivity is lower in children than in adults [13]. Therefore, a non-invasive and high accuracy diagnostic tool is needed for the diagnosis of avulsion fracture in children.

With recent improvements in image quality, ultrasonography has been used as a first-line imaging modality for pediatric foot and ankle injuries [14-16]. Sonographic examination of ankle trauma can be immediately performed in an outpatient clinic and reduces the need for radiography [14]. Furthermore, ultrasonography can also visualize small avulsion fractures and unossified epiphyses $[8,14]$. Thus, ultrasonography can often reveal a fracture that may overlooked on standard radiographs [17]. These characteristics make it particularly suitable for the diagnosis of avulsion fractures of the distal fibula. Additionally, ultrasonography can visualize ligament injuries that cannot be evaluated by radiographs [18]. However, the diagnostic accuracy of ultrasonography in detecting avulsion fractures of the distal fibula has not been clarified or compared with that of radiography.

The purpose of this study was to determine the diagnostic accuracy of ultrasonography for the diagnosis of avulsion fractures of the distal fibula concomitant with lateral ankle sprain in children and compare to radiography. We hypothesized that the diagnostic accuracy of ultrasonography was comparable to that of radiography.

\section{Methods \\ Patient recruitment}

Patients who visited 4 local orthopaedic clinics complaining of lateral ankle sprain between December 2016 and November 2018 were prospectively screened for eligibility. Inclusion criteria were age between 6 to 12 years [1], inversion ankle sprain, presence of swelling and tenderness localized to the lateral malleolus [19], and inability to walk for 4 or more steps on presentation to the clinic [20]. Exclusion criteria were open fracture, multiple trauma, midfoot injury, history of ankle surgery, and epiphyseal arrest. Patients who visited the clinics more than $72 \mathrm{~h}$ after the injury $[21,22]$ and those who had undergone treatment at other facilities before presenting to the clinics were also excluded. Patients with a history of ankle sprain were not excluded to replicate the clinical setting. Finally, patients who did not consent to participate in this study were excluded. Of the 64 patients screened for eligibility, 10 patients were excluded (Fig. 1). The remaining 54 patients underwent both sonographic and radiographic examinations on the first visit. Two patients were lost to follow-up, and the remaining 52 underwent follow-up radiographs 4 weeks later. There were 28 females and 24 males with a median age of 9 (25th, 75th percentile values; 8,10$)$ years. Median height, weight, and body mass index were $1.33(1.25,1.44)$ $\mathrm{m}, 28.0(24.0,36.0) \mathrm{kg}$, and $16.4(1.54,17.6) \mathrm{kg} / \mathrm{m}^{2,}$ respectively. Eight patients (15\%) had a previous history of ipsilateral ankle sprain. The institutional review board of our clinics approved this study, and all subjects and their parents provided written informed consent.

\section{Ultrasonography}

Patients underwent ultrasonography at the first visit to clinics, before undergoing radiography. Patients were seated on the edge of the examination bed with the 


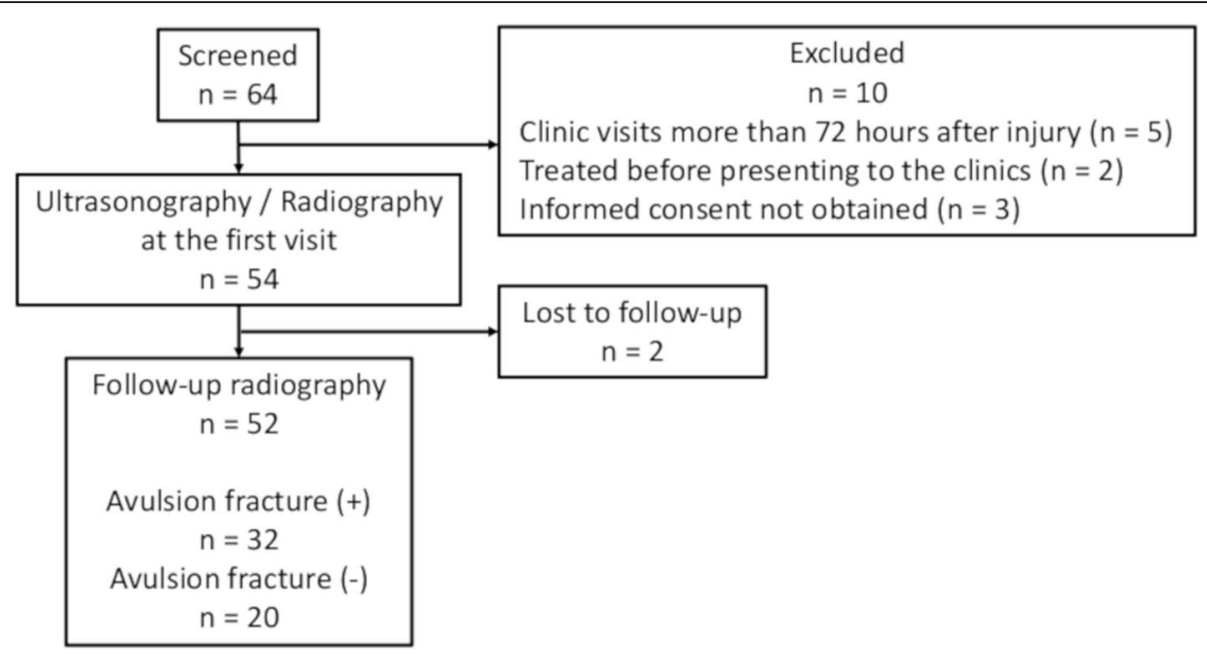

Fig. 1 Flow diagram of patients

ankle slightly plantarflexed, inverted, and placed on the examiner's thigh $[23,24]$. The probe was placed parallel to the sole to visualize the longitudinal view of the ATFL $[18,23,24]$. Then, the probe was moved proximally and distally to check for avulsion fracture and ATFL injury along the entire width of the ligament [8]. The presence of fractures in other areas of the fibula, defined as disruption or stepping of the cortical bone, was also assessed using axial and longitudinal views of the bone [14]. The examiners scanned both ankles in all subjects because epiphyseal bones with irregular contours often require comparison with the uninjured side for accurate diagnosis [17]. The examination was performed using B mode images. Doppler ultrasonography was not used. The sonographic findings were classified as avulsion fracture of the distal fibula (Fig. 2a), subfibular ossicle (Fig. 2b), epiphyseal injury of the distal fibula, ATFL injury (Fig. 2c), and no ligamentous or osseous injury (Fig. $2 d)$. Avulsion fracture of the distal fibula, as well as epiphyseal fracture, was defined as disruption or stepping of the cortical bone $[8,25]$. Subfibular ossicle could include old, nonunited avulsion fractures and secondary ossification centers [26]. While avulsion fractures generally have a shell-like appearance, subfibular ossicles have a round shape with a cortical margin [3]. ATFL injury was defined as a disruption of the fibrillar pattern of the ligament [18]. The diagnoses were further dichotomized into presence or absence of avulsion fracture. Four certified orthopaedic surgeons performed the ultrasonography. Each surgeon had previous experience of more than 3 years with musculoskeletal ultrasonography. The ultrasound machine (LOGIQ e Premium, GE Healthcare, Chicago, Illinois, USA; SONIMAGE HS1, Konica Minolta Healthcare, Marunouchi, Tokyo, Japan) and probe (Linear probe L8-18i-RS, frequency $7-18 \mathrm{MHz}$, length
$35 \mathrm{~mm}$, GE Healthcare, Chicago, Illinois, USA; Linear probe L18-4, center frequency $10 \mathrm{MHz}$, length $40 \mathrm{~mm}$, Konica Minolta Healthcare, Marunouchi, Tokyo, Japan) varied depending on the clinic. As the 4 examiners were also the treating surgeons, they were not blinded to the subject characteristics and physical examination finding; however, they were blinded to the alternative radiographic findings because the radiographic examination was performed after the ultrasonography. This study setting is representative of how ultrasonography is used in clinical practice.

\section{Radiography}

For all patients, radiographic imaging was performed for both ankles (in mortise, lateral, and ATFL views) on their first visit to the clinics, after ultrasonography. The ATFL view [10] has higher sensitivity for detecting avulsion fractures of the distal fibula than the more conventional mortise and lateral views $[5,9]$. The radiographic findings were categorized into avulsion fracture of the distal fibula (Fig. 3), subfibular ossicle, epiphyseal fracture, and no fracture. Diagnosis of avulsion fracture was made if cortical disruption with a shell-like bone fragment was present in at least 1 of the 3 images taken [10]. The diagnoses were further classified according to the presence or absence of avulsion fracture. As the treating surgeons performed the sonographic examination before radiography, they were not able to assess the radiography in a blinded fashion. Therefore, another certified orthopaedic surgeon-who was not involved in the treatment of subjects and was blinded to the sonographic findings-evaluated all radiographic images. The surgeon had an experience of 7 years in assessing musculoskeletal radiographs. 

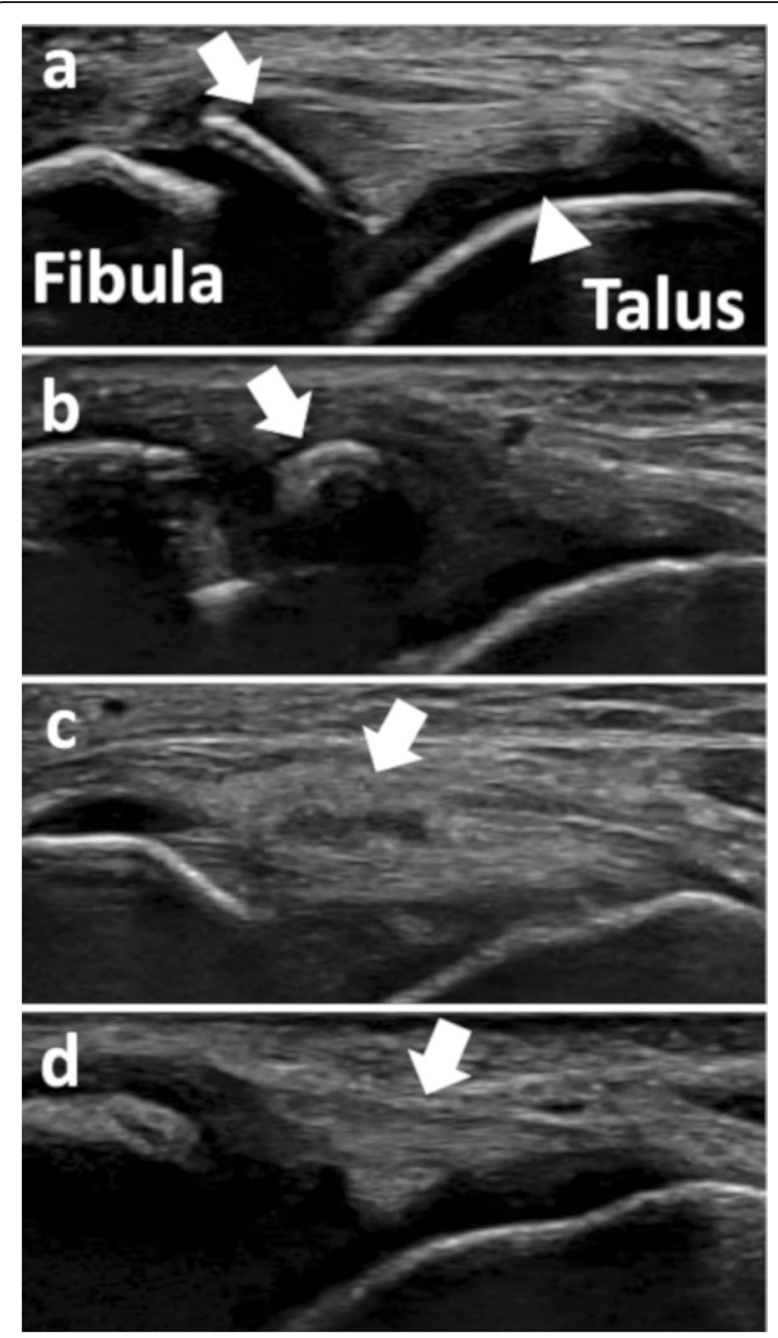

Fig. 2 Sonographic image of the longitudinal view of the anterior talofibular ligament. a Avulsion fracture (arrow) at the fibular insertion of the anterior talofibular ligament (arrowhead), $\mathbf{b}$ Subfibular ossicle (arrow), c Anterior tibiofibular ligament injury (arrow), d No osseous or ligamentous injury (arrow)

\section{Reference standard}

At least 4 weeks after the first visit, the patients underwent the same set of radiographic examinations on the injured ankle. The treatment method between visits was not standardized and was selected by the patient, their parents, and the treating physician regardless of the presence of avulsion fracture. Treatments ranged from symptomatic treatment with an elastic bandage to the use of a non-weight-bearing below-knee cast for 4 weeks. The evaluation of the follow-up radiographs served as the reference standard for the diagnosis of avulsion fracture. This was because small avulsion fragments, which had not been visible on the initial sonographic and radiographic images, would later ossify and enlarge enough to appear on the follow-up radiographs [12, 27, 28]. Therefore, the follow-up radiographs have been used as the reference standard for the assessment of diagnostic accuracy of ultrasonography for detecting occult ankle fractures [27, 28]. A certified orthopaedic surgeon, who was not involved in the treatment of patients and was blinded to the initial sonographic and radiographic diagnoses, evaluated all radiographic images using the same criteria as that of the initial radiographs. The surgeon had an experience of 17 years in assessing musculoskeletal radiographs. Additionally, we diagnosed the case as fracture if callus formation was noted [26]. The kappa values for intra- and inter-observer reliability in the diagnosis of avulsion fracture were 1.00 and 0.92 , respectively.

\section{Statistics}

Sensitivity, specificity, positive predictive value (PPV), and negative predictive value (NPV) (with 95\% confidence interval) for the diagnosis of avulsion fracture of the distal fibula were calculated for ultrasonography and radiography at the first visit, by comparison to the follow-up radiography (i.e. the reference standard). The diagnostic performance measures were calculated using the following equations:

\begin{tabular}{lll}
\hline $\begin{array}{l}\text { Ultrasonography/ } \\
\text { radiography at first } \\
\text { visit }\end{array}$ & \multicolumn{2}{l}{ Radiography at follow-up (Reference standard) } \\
\cline { 2 - 3 } Avulsion fracture (+) & Avulsion fracture (-) \\
\hline Avulsion fracture (+) & True-positive (TP) & False-positive (FP) \\
Avulsion fracture (-) & False-negative (FN) & True-negative (TN) \\
\hline
\end{tabular}

Sensitivity $=T P /(T P+F N)$

Specificity $=T N /(T N+F P)$

$P P V=T P /(T P+F P)$

$\mathrm{NPV}=\mathrm{TN} /(\mathrm{FN}+\mathrm{TN})$

The sensitivities and specificities of the diagnoses made using ultrasonography and radiography were compared using a two-sided McNemar test [29]. Agreement between the diagnoses made using ultrasonography and radiography done at the first visit was assessed using kappa statistics. Furthermore, the diagnostic performance measures for the overall diagnoses, including those of subfibular ossicle and epiphyseal fracture were calculated. A $P$ value of less than 0.05 was considered statistically significant.

\section{Results}

On the follow-up (reference standard) radiographs, 32 patients (62\%) were diagnosed as avulsion fractures of the distal fibula (Table 1). On the ultrasonography and radiography at the first visit, $33(63 \%)$ and 26 (50\%) patients were diagnosed with avulsion fractures, respectively.

The sensitivity and specificity of ultrasonography were 94\% (95\% confidence interval; 79, 99\%) and 85\% (62, 97\%) respectively, with the PPV and NPV at 91\% (76, $98 \%)$ and $89 \%(67,99 \%)$ respectively (Table 2$)$. Of the 2 


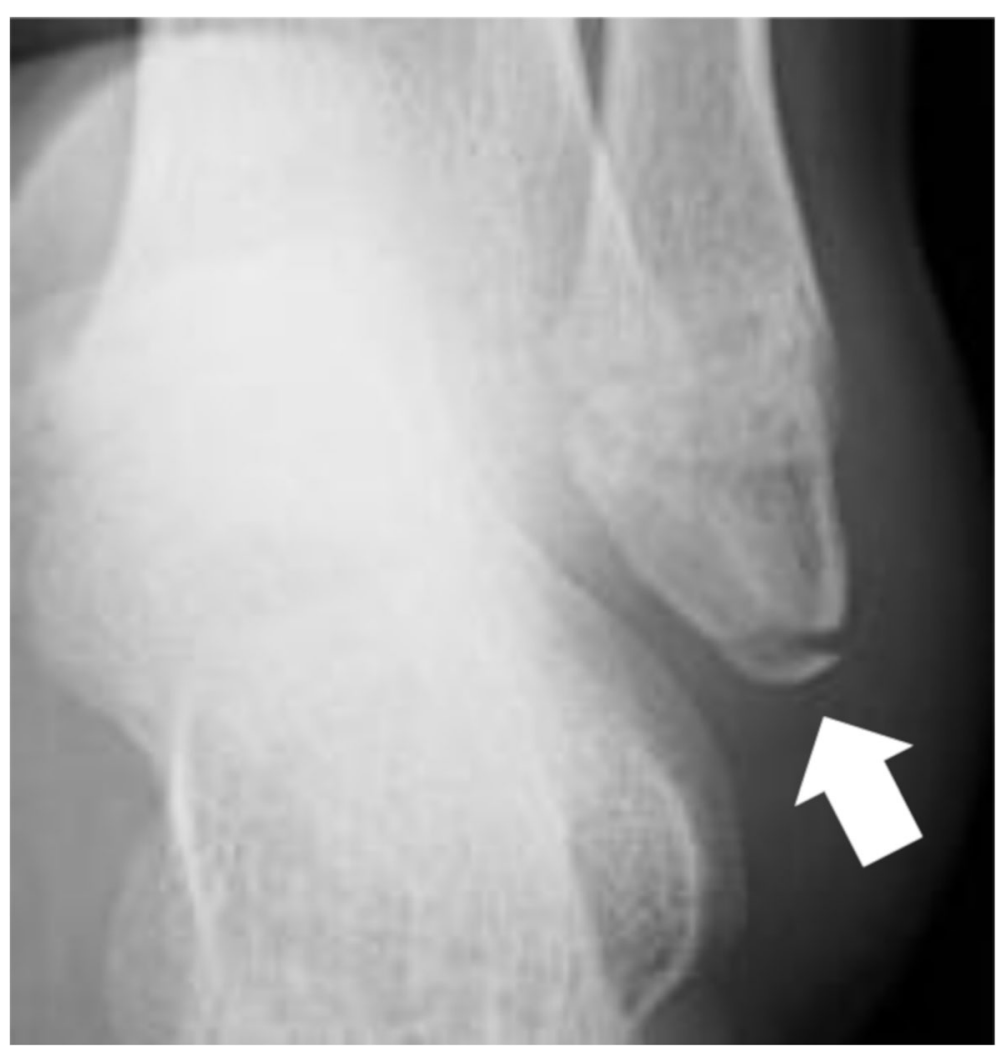

Fig. 3 Anterior talofibular ligament view of the ankle. An avulsion fracture of the distal fibula is visualized (arrow)

false-negative diagnoses, 1 was diagnosed as subfibular ossicle and the other 1 was diagnosed as no injury on the initial ultrasonography. For the 3 false-positive diagnoses, the diagnoses of the follow-up radiographs were no injury in all cases. The sensitivity and specificity of radiography were $81 \%(64,93 \%)$ and $100 \%$, respectively, with the PPV and NPV of 100 and 77\% (56, 91\%), respectively (Table 3). Of the 6 false-negative diagnoses, 1 was diagnosed as subfibular ossicle and 5 were diagnosed as no injury on the initial radiographs. There were no statistical differences in the sensitivities and specificities between the two diagnostic imaging techniques $(P=0.22$ and 0.25 for sensitivity and specificity, respectively). The kappa coefficient for the agreement of ultrasonographic and radiographic diagnoses at the first visit was $0.65(0.46,0.85)$.
Of the 26 patients who were diagnosed with avulsion fracture of the distal fibula on the initial radiographs at the initial visit, all fractures were visible on the ATFL view. However, only 15 fractures were depicted on the standard mortise and lateral views.

The sensitivity and specificity of ultrasonography for overall diagnosis, including those of subfibular ossicle and epiphyseal fracture, were 94\% (79, 99\%) and 75\% (51, 91\%), respectively, with the PPV and NPV of $86 \%$ (70, 95\%) and $88 \%(64,99 \%)$ (Table 4). In addition to the 3 false-positive diagnoses for avulsion fracture as described above, the ultrasonographic diagnosis of epiphyseal fracture was determined to be a false positive due to the absence of callus or periosteal reaction on the follow-up radiographs. The diagnostic performance

Table 1 Diagnosis of ultrasonography and radiography at the first visit and follow-up $(n=52)$

\begin{tabular}{llll}
\hline & Ultrasonography at first visit & Radiography at first visit & Radiography at follow-up (Reference standard) \\
\hline Avulsion fracture at the distal fibula & $33(63)$ & $26(50)$ & $32(62)$ \\
Subfibular ossicle & $2(4)$ & $2(4)$ & $1(2)$ \\
Epiphyseal fracture & $2(4)$ & $0(0)$ & $0(0)$ \\
Anterior talofibular ligament injury & $5(10)$ & n.a. & n.a. \\
No osseous (or ligamentous) injury & $10(19)$ & $24(46)$ & $19(37)$ \\
\hline
\end{tabular}

Values show the number (percent) of patients n.a. not applicable 
Table 2 Diagnosis of avulsion fracture using ultrasonography at the first visit in relation to reference diagnosis using follow-up radiography $(n=52)$

\begin{tabular}{llll}
\hline $\begin{array}{l}\text { Ultrasonography at } \\
\text { first visit }\end{array}$ & \multicolumn{2}{l}{$\begin{array}{l}\text { Radiography at follow-up } \\
\text { (Reference standard) }\end{array}$} & Total \\
\cline { 2 - 3 } & Fracture $(+)$ & Fracture $(-)$ & \\
\hline Avulsion fracture $(+)$ & 30 & 3 & 33 \\
Avulsion fracture $(-)$ & 2 & 17 & 19 \\
Total & 32 & 20 & \\
\hline
\end{tabular}

Values show the number of patients

measures of radiography for overall diagnosis were the same as those for the diagnosis of avulsion fracture.

\section{Discussion}

We showed that the diagnostic accuracy of ultrasonography for the diagnosis of avulsion fracture of the distal fibula was comparable to that of radiography, with a sensitivity and specificity of over $85 \%$. Ultrasonography may be used as the first-line imaging investigation for lateral ankle sprain in children as an alternative to radiography.

The sensitivity and specificity of ultrasonography was 94 and $85 \%$, respectively. These values were comparable to those of sonographic diagnosis of foot and ankle fractures in adults [15, 30,31], although, in these studies, most fractures were malleolar and metatarsal fractures. Szczepaniak et al. [25] performed ultrasonography on 212 children who had sustained lateral ankle sprains. They detected avulsion fractures in $29 \%$ of patients; however, the authors [25] did not report the diagnostic accuracy of ultrasonography. NajafZadeh et al. [27] reported in their meta-analysis on occult fractures in children, that the sensitivity and specificity of ultrasonography for the diagnosis of occult ankle fractures were 100 and 95\% respectively. Unfortunately, avulsion fractures of the distal fibula were not assessed. Our study showed that ultrasonography was also effective in detecting avulsion fractures.

Although the overall diagnostic accuracy of ultrasonography was as high as that of radiography, there were 3 false-positive and 2 false-negative results in the diagnosis of avulsion fracture. Additional falsepositive diagnoses, in which sonographic diagnosis of

Table 3 Diagnosis of avulsion fracture using radiography at the first visit in relation to reference diagnosis using follow-up radiography $(n=52)$

\begin{tabular}{llll}
\hline $\begin{array}{l}\text { Radiography at first } \\
\text { visit }\end{array}$ & \multicolumn{2}{l}{$\begin{array}{l}\text { Radiography at follow-up } \\
\text { (Reference standard) }\end{array}$} & Total \\
\cline { 2 - 3 } & Fracture $(+)$ & Fracture $(-)$ & \\
\hline Avulsion fracture $(+)$ & 26 & 0 & 26 \\
Avulsion fracture $(-)$ & 6 & 20 & 26 \\
Total & 32 & 20 & \\
\hline
\end{tabular}

Values show the number of patients
Table 4 Diagnosis of overall fracture using ultrasonography in relation to reference diagnosis using follow-up radiography $(n=52)$

\begin{tabular}{llll}
\hline $\begin{array}{l}\text { Ultrasonography } \\
\text { at first visit }\end{array}$ & \multicolumn{2}{l}{$\begin{array}{l}\text { Radiography at follow-up } \\
\text { (Reference standard) }\end{array}$} & Total \\
\cline { 2 - 3 } & Fracture $(+)$ & Fracture $(-)$ & \\
\hline Overall fracture $(+)$ & 30 & 5 & 35 \\
Overall fracture $(-)$ & 2 & 15 & 17 \\
Total & 32 & 20 & \\
\hline
\end{tabular}

Values show the number of patients

epiphyseal fracture of the lateral malleolus was determined to be no osseous injury according to the followup radiographs, occurred in 2 patients. Both falsepositive and false- negative results have been reported in the sonographic diagnosis of foot and ankle fractures in adults $[15,16,30]$. The use of Doppler sonography could improve the accuracy because Doppler signals appear around the acute fracture site due to hematoma and increased blood flow [4,32]. Therefore, it may be used to distinguish an acute avulsion fracture from a subfibular ossicle, and to distinguish an epiphyseal fracture from a natural irregularity of epiphysis; however, further research is necessary to clarify the usefulness of Doppler ultrasonography [32]. Furthermore, treating physicians should inform patients and their parents about the possibility of a false positive or false negative diagnosis.

Even though the ATFL views were obtained in this study, the sensitivity of radiography for the diagnosis of avulsion fracture was $81 \%$ : 6 of the 26 avulsion fractures were missed on the initial radiographs. One possible reason for the relatively high incidence of false negative diagnoses was that chondral avulsions were not visualized on the initial radiographs. These later ossified and appeared on the followup radiographs [12, 27, 28]. Although controversy exists, accurate diagnosis of avulsion fractures of the distal fibula would be clinically important because Yamaguchi et al. [5] showed that the incidence rate of recurrent sprain was $44 \%$ in patients with avulsion fractures, as compared to $23 \%$ in those without fractures. Vahvanen et al. [33] also reported the poorer clinical outcome in patients with avulsion fractures than in those without fractures. Therefore, patients and their parents should be informed that the avulsion fracture may become evident on follow-up radiographs even though the fracture was not clear on the initial radiographs.

There were no significant differences in sensitivity and specificity between the two diagnostic imaging techniques. Thus, treating physicians can select either modality for the diagnosis of avulsion fracture, based on their experience and the availability of the equipment. Ultrasonography has several advantages over radiography [17]; ultrasonography does not expose the patient to radiation. It is immediately available in the outpatient room and can be used even outside the clinics with portable machines. It also leads to substantial cost reduction when used appropriately. 
Additionally, soft tissue injuries associated with bone injury can be assessed simultaneously. However, it is not clear if ultrasonography can also be used for the follow-up examination such as for the assessment of fracture healing. Therefore, ultrasonography cannot fully replace radiography but it may be used as a screening tool to decrease the risk of radiation hazard [14].

With the recent development of high-frequency ultrasonography transducers, the role of ultrasonography in orthopaedic surgery, not only as a diagnostic tool but also as a therapeutic and research tool, has been increasingly recognized [34]. Similar to other medical fields [35], surgeonperformed ultrasonography has become increasingly common among orthopaedic surgeons. However, we acknowledge that it would be difficult for many orthopaedic surgeons to perform ultrasonography on a routine basis due to limited time, cost, and experience. In these circumstances, radiologists and other experienced examiners can perform ultrasonography [36]. Further research is needed on the clinical availability of ultrasonography, although this issue is beyond the scope of this study.

This study has several limitations. Firstly, the certified orthopaedic surgeons, with experiences of more than 3 years in musculoskeletal ultrasonography, performed the ultrasonography. Therefore, the results of this study may not be applicable if less experienced examiners perform ultrasonography [36]. Secondly, we did not assess the reliability of the sonographic diagnosis over time due to limited time, as the examiners were in a clinical practice setting. Studies have shown that the intra-and inter-rater reliability of foot structure assessment is satisfactory [37, 38]. However, further research is warranted to clarify the reliability of fracture detection, although repeated examinations would be difficult on pediatric trauma patients. Thirdly, 2 patients who underwent the index examinations were lost to follow-up radiography; this might have affected the diagnostic accuracy. Fourthly, the ultrasound machines were different among the clinics, which might have affected the diagnostic performance. Finally, clinical information, such as physical examination findings, was available to the sonographic examiners because they were the treating surgeons.; however, it was not available to the radiographic examiners. Therefore, the diagnostic accuracy of radiography might have been lower than that routinely observed in clinical practice. Finally, the number of patients was relatively small.

\section{Conclusions}

In conclusion, ultrasonography, performed by experienced examiners, has a high diagnostic accuracy, which is comparable to that of radiography for the diagnosis of avulsion fracture of the distal fibula. Ultrasonography may therefore be used as an alternative to radiography for lateral ankle sprain in children.
Abbreviations

ATFL: Anterior talofibular ligament; CFL: Calcaneofibular ligament

\section{Acknowledgements}

Not applicable.

\section{Authors' contributions}

YT, SY, RA, MK, SK, HT, and TY designed the study. YT, RA, MK, HT, and TY recruited the patients. SK performed radiographic analysis. SY and SK collected the patient data. SY and MK performed statistical analysis. YT and SY drafted the manuscript with input from the other authors. All authors read and approved the final manuscript.

\section{Funding}

The authors received no financial support for this research.

Availability of data and materials

The datasets used and/or analyzed during the current study are available from the corresponding author on reasonable request.

Ethics approval and consent to participate

The Research Ethics Committee of the Graduate School of Medicine, Chiba University approved this study (approval number: 2751), and all patients and their parents provided written informed consent.

\section{Consent for publication}

All patients and their parents provided written consent to use their clinical and imaging data.

\section{Competing interests}

The authors declare that they have no competing interests.

\section{Author details}

${ }^{1}$ Takakura Orthopaedic \& Sports Clinic, 5-4-21 Tokui-cho, Nada-ku, Kobe-shi, Hyogo 657-0033, Japan. ${ }^{2}$ Collage of Liberal Arts and Sciences, Chiba University, 1-8-1 Inohana, Chuo-ku, Chiba-shi, Chiba 260-8670, Japan. ${ }^{3}$ Department of Orthopaedic Surgery, Graduate School of Medical and Pharmaceutical Sciences, Chiba University, 1-8-1 Inohana, Chuo-ku, Chiba-shi, Chiba 260-8670, Japan. ${ }^{4}$ Chiba C \& A Orthopaedic Clinic, 3-24-2

Oyumino-minami, Midori-ku, Chiba-shi, Chiba 266-0033, Japan. ${ }^{5}$ Hyakutake Orthopedic Surgery and Sports Clinic, 4-2-15 Mizugae, Saga-shi, Saga 840-0054, Japan. ${ }^{6}$ Department of Orthopaedic Surgery, Teikyo University Mizonokuchi Hospital, 5-1-1 Futako, Takatsu-ku, Kawasaki-shi, Kanagawa 213-8507, Japan.

Received: 24 December 2019 Accepted: 13 April 2020

Published online: 28 April 2020

\section{References}

1. Doherty C, Delahunt E, Caulfield B, Hertel J, Ryan J, Bleakley C. The incidence and prevalence of ankle sprain injury: a systematic review and meta-analysis of prospective epidemiological studies. Sports Med. 2014; 44(1):123-40.

2. Diallo J, Wagener J, Schweizer C, Lang TH, Ruiz R, Hintermann B. Intraoperative findings of lateral ligament avulsion fractures and outcome after Refixation to the fibula. Foot Ankle Int. 2018;39:669-73. https://doi.org/ 10.1177/1071100718760273.

3. Haraguchi N, Toga H, Shiba N, Kato F. Avulsion fracture of the lateral ankle ligament complex in severe inversion injury: incidence and clinical outcome. Am J Sports Med. 2007;35(7):1144-52

4. Kwak YH, Lim JY, Oh MK, Kim WJ, Park KB. Radiographic diagnosis of occult distal fibular avulsion fracture in children with acute lateral ankle sprain. J Pediatr Orthop. 2015:35(4):352-7.

5. Yamaguchi S, Akagi R, Kimura S, Sadamasu A, Nakagawa R, Sato Y, Kamegaya M, Sasho T, Ohtori S. Avulsion fracture of the distal fibula is associated with recurrent sprain after ankle sprain in children. Knee Surg Sports Traumatol Arthrosc. 2018:27:2774-80.

6. Boutis K, Plint A, Stimec J, Miller E, Babyn P, Schuh S, Brison R, Lawton L, Narayanan UG. Radiograph-negative lateral ankle injuries in children: occult growth plate fracture or sprain? JAMA Pediatr. 2016;170(1):e154114. 
7. Pill SG, Hatch M, Linton JM, Davidson RS. Chronic symptomatic os subfibulare in children. J Bone Joint Surg Am. 2013;95(16):e115 (111-116).

8. Maeda M, Maeda N, Takaoka T, Tanaka Y. Sonographic findings of Chondral avulsion fractures of the lateral ankle ligaments in children. J Ultrasound Med. 2017;36(2):421-32.

9. Noh JH, Yang BG, Yi SR, Lee $\mathrm{SH}$, Song $\mathrm{CH}$. Outcome of the functional treatment of first-time ankle inversion injury. J Orthop Sci. 2010;15(4):52430.

10. Haraguchi N, Kato F, Hayashi H. New radiographic projections for avulsion fractures of the lateral malleolus. J Bone Joint Surg Br. 1998;80(4):684-8.

11. Alzen G, Benz-Bohm G. Radiation protection in pediatric radiology. Dtsch Arztebl Int. 2011;108(24):407-14.

12. Busconi BD, Pappas AM. Chronic, painful ankle instability in skeletally immature athletes. Ununited osteochondral fractures of the distal fibula. Am J Sports Med. 1996;24(5):647-51.

13. Beckenkamp PR, Lin CC, Macaskill P, Michaleff ZA, Maher CG, Moseley AM. Diagnostic accuracy of the Ottawa ankle and Midfoot rules: a systematic review with meta-analysis. Br J Sports Med. 2017;51(6):504-10.

14. Hedelin H, Goksör L, Karlsson J, Stjernström S. Ultrasound-assisted triage of ankle trauma can decrease the need for radiographic imaging. Am J Emerg Med. 2013;31(12):1686-9

15. Canagasabey MD, Callaghan MJ, Carley S. The sonographic Ottawa foot and ankle rules study (the SOFAR study). Emerg Med J. 2011;28(10):838-40.

16. Ozturk P, Aksay E, Oray NC, Bayram B, Basci O, Tokgoz D. Emergency physician accuracy using ultrasonography to diagnose lateral malleolar fracture. Am J Emerg Med. 2018;36(3):362-5.

17. Hoffman DF, Adams E, Bianchi S. Ultrasonography of fractures in sports medicine. Br J Sports Med. 2015;49(3):152-60.

18. Kemmochi M, Sasaki S, Fujisaki K, Oguri Y, Kotani A, Ichimura S. A new classification of anterior talofibular ligament injuries based on ultrasonography findings. J Orthop Sci. 2016;21(6):770-8.

19. Boutis K, Komar L, Jaramillo D, Babyn P, Alman B, Snyder B, Mandl KD, Schuh S. Sensitivity of a clinical examination to predict need for radiography in children with ankle injuries: a prospective study. Lancet. 2001;358(9299):2118-21.

20. Clark KD, Tanner S. Evaluation of the Ottawa ankle rules in children. Pediatr Emerg Care. 2003;19(2):73-8.

21. Boutis K, Willan AR, Babyn P, Narayanan UG, Alman B, Schuh S. A randomized, controlled trial of a removable brace versus casting in children with low-risk ankle fractures. Pediatrics. 2007;119(6):e1256-63.

22. Gravel J, Hedrei P, Grimard G, Gouin S. Prospective validation and head-tohead comparison of 3 ankle rules in a pediatric population. Ann Emerg Med. 2009;54(4):534-540.e531.

23. Oae K, Takao M, Uchio Y, Ochi M. Evaluation of anterior talofibular ligament injury with stress radiography, ultrasonography and MR imaging. Skelet Radiol. 2010;39(1):41-7.

24. Cho JH, Lee DH, Song HK, Bang JY, Lee KT, Park YU. Value of stress ultrasound for the diagnosis of chronic ankle instability compared to manual anterior drawer test, stress radiography, magnetic resonance imaging, and arthroscopy. Knee Surg Sports Traumatol Arthrosc. 2016;24(4): 1022-8.

25. Szczepaniak J, Ciszkowska-Łysoń B, Śmigielski R, Zdanowicz U. Value of ultrasonography in assessment of recent injury of anterior talofibular ligament in children. J Ultrason. 2015;15(62):259-66.

26. Ahn HW, Lee KB. Comparison of the modified Broström procedure for chronic lateral ankle instability with and without subfibular Ossicle. Am J Sports Med. 2016;44(12):3158-64.

27. Najaf-Zadeh A, Nectoux E, Dubos F, Happiette L, Demondion X, Gnansounou M, Herbaux B, Martinot A. Prevalence and clinical significance of occult fractures in children with radiograph-negative acute ankle injury. A meta-analysis. Acta Orthop. 2014;85(5):518-24.

28. Simanovsky N, Hiller N, Leibner E. Sonographic detection of radiographically occult fractures in paediatric ankle injuries. Pediatr Radiol. 2005;35(11):1062-5.

29. McNemar Q. Note on the sampling error of the difference between correlated proportions or percentages. Psychometrika. 1947;12(2):153-7.

30. Atilla OD, Yesilaras M, Kilic TY, Tur FC, Reisoglu A, Sever M, Aksay E. The accuracy of bedside ultrasonography as a diagnostic tool for fractures in the ankle and foot. Acad Emerg Med. 2014;21(9):1058-61.

31. Ekinci $S$, Polat $O$, Günalp M, Demirkan A, Koca A. The accuracy of ultrasound evaluation in foot and ankle trauma. Am J Emerg Med. 2013;31(11):1551-5.
32. Oh MJ, Park KT, Youn KM, Joo JC, Park SJ. Color Doppler Sonography accompanied by dynamic scanning for the diagnosis of ankle and foot fractures. J Ultrasound Med. 2018;37(6):1555-64.

33. Vahvanen V, Westerlund M, Kajanti M. Sprained ankle in children. A clinical follow-up study of 90 children treated conservatively and by surgery. Ann Chir Gynaecol. 1983;72(2):71-5.

34. Apard T. Ultrasonography for the orthopaedic surgeon. Orthop Traumatol Surg Res. 2019;105(1S):S7-S14.

35. Pereira J, Bass GA, Mariani D, Dumbrava BD, Casamassima A, da Silva AR, Pinheiro L, Martinez-Casas I, Zago M. Surgeon-performed point-of-care ultrasound for acute cholecystitis: indications and limitations: a European Society for Trauma and Emergency Surgery (ESTES) consensus statement. Eur J Trauma Emerg Surg. 2019;46:173-83.

36. Kristen KH, und Aspang JS, Wiedemann J, Hartenbach F, Platzgummer $\mathrm{H}$. Reliability of ultrasonography measurement of the anterior talofibular ligament (ATFL) length in healthy subjects (in vivo), based on examiner experience and patient positioning. J Exp Orthop. 2019;6(1):30.

37. Crofts G, Angin S, Mickle KJ, Hill S, Nester CJ. Reliability of ultrasound for measurement of selected foot structures. Gait Posture. 2014;39(1):35-9.

38. Lee SH, Yun SJ. The feasibility of point-of-care ankle ultrasound examination in patients with recurrent ankle sprain and chronic ankle instability: comparison with magnetic resonance imaging. Injury. 2017:48(10):2323-8.

\section{Publisher's Note}

Springer Nature remains neutral with regard to jurisdictional claims in published maps and institutional affiliations.

Ready to submit your research? Choose BMC and benefit from:

- fast, convenient online submission

- thorough peer review by experienced researchers in your field

- rapid publication on acceptance

- support for research data, including large and complex data types

- gold Open Access which fosters wider collaboration and increased citations

- maximum visibility for your research: over $100 \mathrm{M}$ website views per year

At $\mathrm{BMC}$, research is always in progress.

Learn more biomedcentral.com/submissions 